\title{
Physician Burnout and Timing of Electronic Health Record Use
}

\author{
Mark A. Micek ${ }^{1,2}$ Brian Arndt ${ }^{2,3}$ Wen-Jan Tuan ${ }^{3}$ Elizabeth Trowbridge ${ }^{1,2}$ Shannon M. Dean ${ }^{4}$ \\ Jennifer Lochner ${ }^{2,3}$ Emmanuel Sampene ${ }^{5}$ Nancy Pandhi ${ }^{2,6}$
}

${ }^{1}$ Department of Medicine, University of Wisconsin School of Medicine
and Public Health, Madison, Wisconsin, United States
2 Primary Care Academics Transforming Healthcare Collaborative, UW
Health, Madison, Wisconsin, United States
${ }^{3}$ Department of Family Medicine and Community Health, University
of Wisconsin School of Medicine and Public Health, Madison,
Wisconsin, United States
${ }^{4}$ Division of Hospital Medicine, Department of Pediatrics, University
of Wisconsin School of Medicine and Public Health, Madison,
Wisconsin, United States
${ }^{5}$ Department of Biostatistics and Medical Informatics, University of
Wisconsin School of Medicine and Public Health, Madison,
Wisconsin, United States
6 Department of Family and Community Medicine, University of New
Mexico Health Sciences Center, Albuquerque, New Mexico, United States

Address for correspondence Mark A. Micek, MD, MPH, Division of General Internal Medicine, Department of Medicine, University of Wisconsin-Madison, 2828 Marshall Court, Suite 100, Madison, WI 53705, United States (e-mail: mamicek@medicine.wisc.edu).

ACI Open 2020;4:e1-e8.

\section{Abstract}

Keywords

- physician burnout

- physician health

- electronic health records
Background Rates of burnout among physicians have been high in recent years. The electronic health record (EHR) is implicated as a major cause of burnout.

Objective This article aimed to determine the association between physician burnout and timing of EHR use in an academic internal medicine primary care practice.

Methods We conducted an observational cohort study using cross-sectional and retrospective data. Participants included primary care physicians in an academic outpatient general internal medicine practice. Burnout was measured with a single-item question via self-reported survey. EHR time was measured using retrospective automated data routinely captured within the institution's EHR. EHR time was separated into four categories: weekday work-hours in-clinic time, weekday work-hours out-of-clinic time, weekday afterhours time, and weekend/holiday after-hours time. Ordinal regression was used to determine the relationship between burnout and EHR time categories.

Results EHR use during in-clinic sessions was related to burnout in both bivariate (odds ratio $[\mathrm{OR}]=1.04,95 \%$ confidence interval $[\mathrm{Cl}]: 1.01,1.06 ; p=0.007$ ) and adjusted ( $\mathrm{OR}=1.07,95 \% \mathrm{Cl}: 1.03,1.1 ; p=0.001)$ analyses. No significant relationships were found between burnout and after-hours EHR use.

Conclusion In this small single-institution study, physician burnout was associated with higher levels of in-clinic EHR use but not after-hours EHR use. Improved understanding of the variability of in-clinic EHR use, and the EHR tasks that are particularly burdensome to physicians, could help lead to interventions that better integrate EHR demands with clinical care and potentially reduce burnout. Further studies including more participants from diverse clinical settings are needed to further understand the relationship between burnout and after-hours EHR use. received

April 24, 2019

accepted after revision

October 14, 2019

\author{
DOI https://doi.org/ \\ 10.1055/s-0039-3401815. \\ ISSN 2566-9346.
}

(c) 2020 Georg Thieme Verlag KG

Stuttgart · New York
License terms

(c) (i) 


\section{Background and Significance}

Burnout among primary care physicians is a major problem in the United States. Forty-eight percent of internal medicine physicians reported at least one symptom of burnout in 2017 , compared with $43.9 \%$ of physicians overall. ${ }^{1}$ In addition to negatively impacting physician health, burnout is also associated with reduced quality of patient care and increased physician turnover, further contributing to health care costs and the shortage of physicians. ${ }^{2-6}$

While many issues can contribute to physician dissatisfaction and burnout, the electronic health record (EHR) increasingly is implicated as a major source of dissatisfaction. ${ }^{7-10}$ Although the EHR offers some benefits to practice, it also pulls physicians' time away from meaningful face-toface patient interactions toward data entry and asynchronous tasks, such as telephone/patient-portal care. ${ }^{7}$ Recent studies confirm that the EHR occupies a large portion of physicians' lives, both during and after traditional workhours. One study found that physicians spent almost half of their work-hours engaged with the EHR. ${ }^{11}$ Another study found that primary care physicians spent almost 6 hours in the EHR per day, including 4.5 hours during, and 1.4 hours outside of, normal clinic hours. ${ }^{12}$

While prior research has identified the link between perceived EHR workload and burnout, it is not clear whether actual patterns of physicians' EHR use are associated with burnout. If such a relationship exists, it would help clarify the role that changing EHR use could have on reducing burnout and perhaps illuminate specific patterns that are particularly related to physician stress.

\section{Objectives}

We conducted a study to determine the association between physician burnout and timing of EHR use in an academic internal medicine primary care practice. We hypothesized that increased time spent in the EHR, particularly outside of normal work-hours, would be associated with higher levels of burnout.

\section{Methods}

\section{Study Population}

Eligible participants included all 58 primary care internal medicine physicians who practiced and managed a primary care clinic panel at 9 of the 10 University of Wisconsin (UW) Health General Internal Medicine (GIM) clinics in the Madison, Wisconsin area. One rural clinic was excluded from this study due to its distinctly different practice environment and workflows. All physicians at these clinics have academic positions at UW-Madison, with practices ranging from full-time clinical work to hybrid practices with variable amounts of teaching, research, and administrative responsibilities. Physicians' clinical work is structured within half-day sessions. At the time of this study, full-time clinicians (1.0 full-time equivalents or [FTE]) were expected to see patients for 27 hours per week in 9 half-day sessions averaging 2.0 patients per hour, with one half-day administrative time per week; providers working clinically less than full-time have reductions in increments of half-day sessions. Full-time physicians are expected to care for a weighted panel ${ }^{13}$ of 1,800 patients, which is adjusted downward proportional to their in-clinic time. Panel is defined as the group of patients assigned to a specific physician as their primary care provider, and for whom that physician team is expected to provide appropriate primary care, including office visits and non-face-to-face care (i.e., responding to telephone and patient-portal messages). Patients are included on a physician's panel as long as they have at least one clinical encounter within the organization in the previous 3 years. The study was approved by the UW-Madison Health Sciences Institutional Review Board.

\section{Study Measures and Data Collection}

Burnout and sociodemographic data (age, marital status, years since residency, years employed at UW) was collected via an electronic survey sent to all eligible physicians in November 2017. Two reminders were sent approximately 1 and 3 weeks later. Burnout was measured with a single item asking physicians to use their own definition of burnout and rate their feelings on a 5-point scale. Response options included the following: (1) I enjoy my work. I have no symptoms of burnout; (2) I am under stress, and don't always have as much energy as I did, but I don't feel burned out; (3) I am definitely burning out and have one or more symptoms of burnout (e.g., emotional exhaustion); (4) the symptoms of burnout that I am experiencing won't go away. I think about work frustrations a lot; and (5) I feel completely burned out. I am at the point where I may need to seek help. This single-item measure was chosen for several reasons. First, it is identical to item used to measure burnout in the Physicians Worklife Survey ${ }^{14}$ as well as the Minimizing Error, Maximizing Outcome (MEMO) study, a multisite study that showed significant relationships between burnout and lower job satisfaction, greater time pressure, poorer work control, more workplace chaos, lower work-life balance, and greater intent to leave the practice. ${ }^{3,15}$ This measure of burnout was also found in another study to be associated with physicians leaving their institution in the subsequent 2 years. ${ }^{6}$ Second, this single-item measure correlates with the emotional exhaustion component of the Maslach Burnout Inventory (MBI). ${ }^{16-18}$ While it does not correlate strongly with the other two subscales of the MBI (depersonalization and personal accomplishment), ${ }^{16}$ prior studies found that the emotional exhaustion subscale, and not the depersonalization subscale, was associated with physicians reducing their work effort ${ }^{4}$ and leaving practices. ${ }^{19}$ Lastly, this singleitem measure has been promoted by the American Medical Association as part of their STEPS Forward program as a method for organizations to measure burnout. ${ }^{20}$

EHR time and visit volumes were determined for all eligible physicians using retrospective automated data from UW Health's EHR system (Epic Systems Corporation, Verona, Wisconsin, United States). One EHR database, event logging records, automatically stores information each time a clinician accesses or moves between modules in the EHR, including the time that the specific process occurs. Sequential time stamps 
can then be used to determine the time providers spend in the EHR. Time for each individual process was truncated at 90 seconds to minimize inclusion of idle time when the EHR was not engaged by the user. $^{12}$ EHR data were captured for the 12 months prior to the burnout survey administration. Since we were interested in the work done by primary care outpatient physicians, we included only EHR data when physicians were logged into their outpatient clinic environment, and excluded data directly related to inpatient practice.

EHR time was categorized as occurring either during the workdays, after-hours-weekdays, or weekends/holidays. The workday was defined as 7:30 am to $5: 29 \mathrm{pm}$, to capture variation in clinic start times (ranging from 7:50 am to 8:00 $\mathrm{am}$ ) and end times (no patients are scheduled after $5 \mathrm{pm}$ ), and included some time before/after clinic to review and finish charting. Workdays were further subdivided into morning (7:30 am to $12: 29 \mathrm{pm})$ and afternoon (12:30 pm to $5: 29 \mathrm{pm}$ ) half-day sessions. Billing data were used to categorize the time for each half-day session as occurring in-clinic ( $\geq 1$ billed office visit during the half-day period) or out-of-clinic (no office visit billed during that half-day period). Visits done by residents were assigned to the supervising (billing) attending. The average EHR time per in-clinic and out-of-clinic session was then calculated by dividing in-clinic and out-of-clinic EHR times by the number of in-clinic and out-of-clinic sessions, respectively. Similarly, the average EHR time for after-hours-weekdays and weekend/holidays was divided by the number of weekday and weekend/holiday days, respectively. The number of days was further adjusted for physicians who started working at UW Health, or took a leave of absence, within the EHR time period of interest.

Administrative records were used to collect physicians' sex and clinical FTE (cFTE). For simplicity, cFTE was defined as the proportion of 10 half-day sessions a provider was expected to be in clinic seeing patients per week.

\section{Analyses}

Descriptive statistics were used to describe participants' demographic and practice characteristics, degree of burnout, and timing of EHR use. Burnout was treated as an ordinal (ordered) variable. While most previous studies used burnout as a dichotomous variable, we chose to use it as an ordinal variable to retain potentially important differences between providers with varying levels of responses, and to maintain power in our analysis. ${ }^{21}$ Bivariate analyses using nonparametric testing (Spearman's rho for two continuous variables, Mann-Whitney $U$-test for continuous-dichotomous variables) examined the unadjusted relationship between burnout/EHR use and demographic and practice characteristics. Ordinal regression was then used to determine the bivariate and adjusted relationships between burnout (dependent variable) and EHR times. The adjusted model included all EHR time categories (excluding total EHR time) as independent variables, as well as potential confounders. Age and sex were automatically included as potential confounders as they were frequently associated with burnout in prior studies. ${ }^{2}$ Visit volume, defined as the total number of visits, was included to adjust for workload; visit volume was felt to adjust for workload better than cFTE, as it changes based on time away from clinic (i.e., due to vacations or conferences), whereas cFTE does not. We included additional demographic/practice characteristics as covariates only if they were significantly related to EHR use or burnout in bivariate analyses $(p<0.05)$. The analyses used EHR data in the 3 months prior to the survey, as this time period was expected to be more relevant to our one-time measurement of burnout, and long enough to reduce susceptibility to month-to-month schedule variations. In addition, sensitivity analyses using different EHR time periods (1, 6, and 12 months prior to the survey) showed similar results. Analyses were conducted using SPSS v. 25 (2017, IBM Corporation, Armonk, New York, United States) and Stata/SE v. 15.1 (2019, StataCorp LLC, College Station, Texas, United States).

\section{Results}

\section{Characterization of Electronic Health Record Use}

Of the 58 eligible physicians for this study, most were female (62\%) with cFTEs ranging from 0.6 to 0.8 . EHR data were available for all 58 physicians, while only 34 (59\%) completed the survey. There were no significant differences in sex, cFTE, number of clinic visits, and EHR use between those that did and did not complete the survey ( - Table 1 ).

The majority of EHR time occurred when physicians were in clinic, where they used the EHR for an average of 141 minutes (2.4 hours) per each half-day session ( - Table 1). Physicians saw an average of 5.6 (standard deviation [SD]: 0.8) patients per session. EHR usage for other time categories was positively skewed, and was relatively low during weekdays when physicians were not in clinic (median: 27 minutes per half-day session, range: 1-129), after-hours during the week (median: 17 minutes per weekday, range: 0-109), and after-hours on weekends/holidays (median: 16 minutes per weekend/holiday day, range: 0-186). While it is difficult to determine the time spent in EHR on a typical weekday because of the variability in physicians' schedules, we estimate that physicians spent approximately 299 minutes (5 hours) on the EHR during a day when they were in clinic for both morning and afternoon sessions (average: 141 minutes for each half-day session, plus a median of 17 minutes per weekday after-hours).

EHR use varied according to physicians' volume in practice, with higher cFTEs and higher visit volumes associated with more total EHR time, half-day in-clinic session EHR time, and weekend/holiday EHR time (-Table 2). Out-ofclinic session EHR time was significantly associated with a higher number of visits, but not with cFTE. No significant relationships were seen between EHR time categories and physicians' age, sex, marital status, or years in practice.

\section{Burnout and Electronic Health Record Use}

Among the 34 survey respondents, the average burnout rating was 2.3 (SD: 0.9 ) on the 1 to 5 scale where higher ratings indicate more burnout. Most respondents scored a 2 ( $n=17,50 \%$ ) on the scale, while only one physician endorsed a 5 (the highest level of burnout). In bivariate analyses, there were no significant relationships $(p<0.05)$ between burnout and sex, age, marital status, years since clinical training, 
Table 1 Characteristics of participants in the study

\begin{tabular}{|c|c|c|c|c|}
\hline Characteristic & $\begin{array}{l}\text { All participants } \\
(n=58)\end{array}$ & $\begin{array}{l}\text { Completed survey } \\
(n=34 ; 59 \%)\end{array}$ & $\begin{array}{l}\text { Did not complete } \\
\text { survey }(n=24 ; 41 \%)\end{array}$ & $p$-Value ${ }^{a}$ \\
\hline Female (\%) & $36(62 \%)$ & $22(65 \%)$ & $14(58 \%)$ & $0.62^{\mathrm{b}}$ \\
\hline \multicolumn{5}{|l|}{ Clinical FTE (\%) } \\
\hline $0-0.5$ & $15(26 \%)$ & $9(26 \%)$ & $6(25 \%)$ & $0.60^{\mathrm{d}}$ \\
\hline $0.6-0.8$ & $29(50 \%)$ & $18(53 \%)$ & $11(46 \%)$ & \\
\hline 0.9 & $14(24 \%)$ & $7(21 \%)$ & $7(29 \%)$ & \\
\hline $\begin{array}{l}\text { Mean number of visits performed in } \\
3 \text { months prior to survey (SD) }\end{array}$ & $394.5(156.6)$ & $398.7(160.6)$ & 388.5 (153.9) & $0.88^{\mathrm{e}}$ \\
\hline $\begin{array}{l}\text { Total time on EHR in } 3 \text { months prior to } \\
\text { survey: mean hours (SD) }\end{array}$ & $238.7(103.6)$ & $248.2(109.5)$ & $225.2(95.4)$ & $0.52^{\mathrm{e}}$ \\
\hline $\begin{array}{l}\text { Mean EHR time per half-day in-clinic } \\
\text { weekday session: minutes (SD) }\end{array}$ & $141(25)$ & $145(27)$ & $135(20)$ & $0.10^{\mathrm{e}}$ \\
\hline $\begin{array}{l}\text { Median }{ }^{f} \text { EHR time per half-day out-of- } \\
\text { clinic weekday session: minutes (range) }\end{array}$ & $27(1,129)$ & $27(2,106)$ & $27(1,129)$ & $0.30^{\mathrm{e}}$ \\
\hline $\begin{array}{l}\text { Median }{ }^{f} \text { EHR time per after-hours } \\
\text { weekday: minutes (range) }\end{array}$ & $17(0,109)$ & $18(0,104)$ & $14(2,109)$ & $0.67^{\mathrm{e}}$ \\
\hline $\begin{array}{l}\text { Median }{ }^{f} \text { EHR time per after-hours } \\
\text { weekend/holiday day: minutes (range) }\end{array}$ & $16(0,186)$ & $16(0,163)$ & $14(0,186)$ & $0.63^{\mathrm{e}}$ \\
\hline Mean age in years $(S D)$ & $N A^{g}$ & $48(10.0)$ & $N A^{g}$ & \\
\hline Mean years since residency (SD) & $N A^{9}$ & $16.5(9.9)$ & $N A^{g}$ & \\
\hline Mean years at UW (SD) & $N A^{9}$ & $11.7(8.3)$ & $N A^{g}$ & \\
\hline \multicolumn{5}{|l|}{ Marital status } \\
\hline Married/Partner & $N A^{9}$ & 32 (94\%) & $N A^{g}$ & \\
\hline Never married & $N A^{g}$ & $2(6 \%)$ & $N A^{g}$ & \\
\hline
\end{tabular}

Abbreviations: EHR, electronic health record; FTE, full-time equivalents; SD, standard deviation.

a $p$-Value compares those that did versus did not complete the survey.

'Pearson's chi-squared.

${ }^{\text {c} C l i n i c a l ~ F T E ~ i s ~ t h e ~ p r o p o r t i o n ~ o f ~ h a l f-d a y ~ s e s s i o n s ~ a ~ p r o v i d e r ~ w a s ~ e x p e c t e d ~ t o ~ b e ~ i n-c l i n i c ~ p e r ~ w e e k . ~}$

dinear trend.

e Mann-Whitney U-test.

${ }^{\mathrm{f}}$ Median reported, due to positively skewed distribution of data.

${ }^{9}$ Not applicable, as information was obtained only via survey.

Table 2 Bivariate relationship between EHR time and clinical FTE/number of visits $(n=34)$

\begin{tabular}{|c|c|c|c|c|c|}
\hline \multirow[t]{2}{*}{ Characteristic } & \multicolumn{5}{|c|}{ EHR time category } \\
\hline & $\begin{array}{l}\text { Total hours of } \\
\text { EHR time } \\
\rho \\
p \text {-value }\end{array}$ & $\begin{array}{l}\text { Minutes per half-day } \\
\text { in-clinic session } \\
\rho \\
p \text {-value }\end{array}$ & $\begin{array}{l}\text { Minutes per half-day } \\
\text { out-of-clinic session } \\
\rho \\
p \text {-value }\end{array}$ & $\begin{array}{l}\text { Minutes per } \\
\text { after-hours weekday } \\
\rho \\
p \text {-value }\end{array}$ & $\begin{array}{l}\text { Minutes per } \\
\text { weekend/holiday } \\
\rho \\
p \text {-value }\end{array}$ \\
\hline Clinical FTE & $\begin{array}{l}0.78 \\
\mathrm{p}<0.001\end{array}$ & $\begin{array}{l}0.51 \\
p=0.002\end{array}$ & $\begin{array}{l}0.31 \\
p=0.08\end{array}$ & $\begin{array}{l}0.19 \\
p=0.27\end{array}$ & $\begin{array}{l}0.37 \\
p=0.03\end{array}$ \\
\hline Number of visits & $\begin{array}{l}0.81 \\
\mathrm{p}<0.001\end{array}$ & $\begin{array}{l}0.46 \\
p=0.006\end{array}$ & $\begin{array}{l}0.35 \\
p=0.04\end{array}$ & $\begin{array}{l}0.24 \\
p=0.18\end{array}$ & $\begin{array}{l}0.36 \\
p=0.04\end{array}$ \\
\hline
\end{tabular}

Abbreviations: EHR, electronic health record; FTE, full-time equivalents; SD, standard deviation; $\rho$, Spearman's rank correlation coefficient.

years at UW Health, cFTE, and visit volume. In unadjusted analyses, higher levels of burnout were associated with more total and in-clinic EHR time ( - Table 3 and -Fig. 1). In models adjusting for age, sex, cFTE, visit volume, and other categories of EHR time, burnout was significantly associated only with in-clinic EHR time and not with out-of-clinic or after-hours EHR time (-Table 3 ).

\section{Discussion}

In this small study of physicians in an academic primary care internal medicine practice, we found that burnout was associated with the amount of EHR use that occurred during clinic sessions. This finding may indicate that physicians with more in-clinic EHR use feel a greater intrusion of the EHR 
Table 3 Relationship between burnout and EHR time $(n=34)$

\begin{tabular}{|c|c|c|}
\hline \multirow[t]{2}{*}{ EHR time category } & \multicolumn{2}{|l|}{ OR } \\
\hline & $\begin{array}{l}\text { Unadjusted }^{\text {a }} \\
\text { OR } \\
(95 \% \mathrm{CI}) \\
\text { p-value }\end{array}$ & $\begin{array}{l}\text { Adjusted }^{\text {b }} \\
\text { OR } \\
(95 \% \mathrm{CI}) \\
p \text {-value }\end{array}$ \\
\hline Total hours of EHR time & $\begin{array}{l}1.007 \\
(1.001,1.01) \\
p=0.03\end{array}$ & NA \\
\hline $\begin{array}{l}\text { Minutes per half-day } \\
\text { in-clinic session }\end{array}$ & $\begin{array}{l}1.04 \\
(1.01,1.06) \\
p=0.007\end{array}$ & $\begin{array}{l}1.07 \\
(1.03,1.1) \\
p=0.001\end{array}$ \\
\hline $\begin{array}{l}\text { Minutes per half-day } \\
\text { out-of-clinic session }\end{array}$ & $\begin{array}{l}1.01 \\
(0.99,1.04) \\
p=0.33\end{array}$ & $\begin{array}{l}0.99 \\
(0.96,1.02) \\
p=0.40\end{array}$ \\
\hline $\begin{array}{l}\text { Minutes per } \\
\text { after-hours weekday }\end{array}$ & $\begin{array}{l}1.01 \\
(0.98,1.03) \\
p=0.61\end{array}$ & $\begin{array}{l}0.99 \\
(0.95,1.02) \\
p=0.45\end{array}$ \\
\hline $\begin{array}{l}\text { Minutes per } \\
\text { weekend/holiday day }\end{array}$ & $\begin{array}{l}1.02 \\
(0.999,1.03) \\
p=0.06\end{array}$ & $\begin{array}{l}1.01 \\
(0.99,1.04) \\
p=0.27\end{array}$ \\
\hline
\end{tabular}

Abbreviations: $\mathrm{Cl}$, confidence interval; EHR, electronic health record; $\mathrm{NA}$, not applicable; OR, odds ratios, determined using ordinal regression with burnout as the dependent variable and EHR time categories as the primary independent variable.

a Unadjusted analysis represents a separate model for each time category.

${ }^{b}$ Adjusted for sex, age, clinical full-time equivalent, number of visits, and other time categories (total EHR time excluded).

pulling them away from meaningful face-to-face interactions toward computer-time and data-entry tasks. ${ }^{7}$ Our result is consistent with prior research reporting that increased clerical burden is associated with burnout and lower job satisfaction. ${ }^{22}$ Certainly, some of the variability in physicians' in-clinic EHR use may be related to different workloads in face-to-face and asynchronous care, which is reflected in our finding that a higher visit volume was associated with more EHR time in most categories. Efforts to understand the amount of EHR time required to care for specific panels of patients may help normalize productivity expectations, and could prevent overly burdensome workloads. However, variability in EHR use may also be related to inefficiencies in EHR-related proficiency and workflows, even among physicians in the same practice setting. Further research could help determine best practices associated with EHR efficiency, as well as identify specific EHR tasks that particularly increase in-clinic EHR time and burnout. This could lead to targeted physician- and organization-level interventions focused on improving EHR efficiency, offloading work from physicians, and better integrating computer-oriented tasks during face-to-face encounters. Indeed, physician satisfaction has been shown to improve with interventions that distribute EHR tasks to other members of the health care team, ${ }^{23,24}$ enhance physicians' EHR efficiency through proficiency training, ${ }^{25,26}$ and improve note documentation. ${ }^{27}$

Our results did not show a consistently significant relationship between after-hours EHR work (often referred to as "pajama time") and burnout. These results are not consistent with prior findings that self-reported time spent at home on work-related tasks negatively impacts physician satisfaction and burnout. ${ }^{2,28}$ Possible reasons for not finding a significant relationship include our low statistical power due to the low number of participants, and our lack of inclusion of personal information-such as the presence of work-home conflictsthat may impact the consequence of after-hours work in individual physicians. ${ }^{2,29}$ It may also be related to the relatively low amount of EHR time we observed in the after-hours periods compared with prior studies. ${ }^{11,12}$ Some of this difference may be attributed to differences in methodologies, as one study used self-report to determine afterhours work, ${ }^{11}$ which might be an inaccurate estimate of objectively measured EHR time outside of clinic. ${ }^{30}$ Another study normalized EHR time to a full-time physician and included weekday and weekend use in after-hours totals. ${ }^{12}$ Nonetheless, physicians in this study had relatively low faceto-face time and patients-per-hour requirements compared with other organizations, which may have resulted in lower after-hours EHR use and limit the generalizability of our findings to settings with higher productivity requirements. Further studies including a larger number of participants from diverse clinical settings, and perhaps examining for threshold effects or looking at maximum (rather than average) after-hours EHR times, are needed to further define the relationship between after-hours EHR work and burnout.

There are several limitations to our study. First, while the response rate to our survey was adequate (59\%), our sample size was low and might have limited our power to detect meaningful relationships. While the demographic characteristics and EHR use of survey responders and nonresponders were not significantly different, the possibility that responders were less-or more-burned out than respondents could affect our results and generalizability. Second, we measured burnout with a single-item question, which may have less validity and discriminatory ability compared with the complete 22-item MBI. We chose a single validated measure to encourage a higher response rate among our small group of physicians. Third, our measure of EHR use was not an exact measure of physician's active engagement with EHR, but rather based on user access logs which cannot discriminate between active or idle time. Fourth, EHR measurements intentionally included only time spent when physicians were logged in to their outpatient environment. Our EHR metric was therefore not a reflection of total EHR work, and some EHR work may have been misclassified if physicians performed inpatient work while logged into their outpatient environment, or vice versa. Nonetheless, we believe this effect would have minimal impact on our results, as only eight respondents (24\%) did inpatient work. Fifth, our EHR metric did not subdivide the type of EHR work performed, such as work for office visit documentation, order entry, billing, telephone calls, or patient-portal messages. Future studies including EHR task categorizations could help identify which EHR tasks may particularly contribute to burnout. Lastly, our sample was restricted to academic internal medicine physicians in one university-based practice setting, so may not be applicable to other academic or nonacademic practices. 

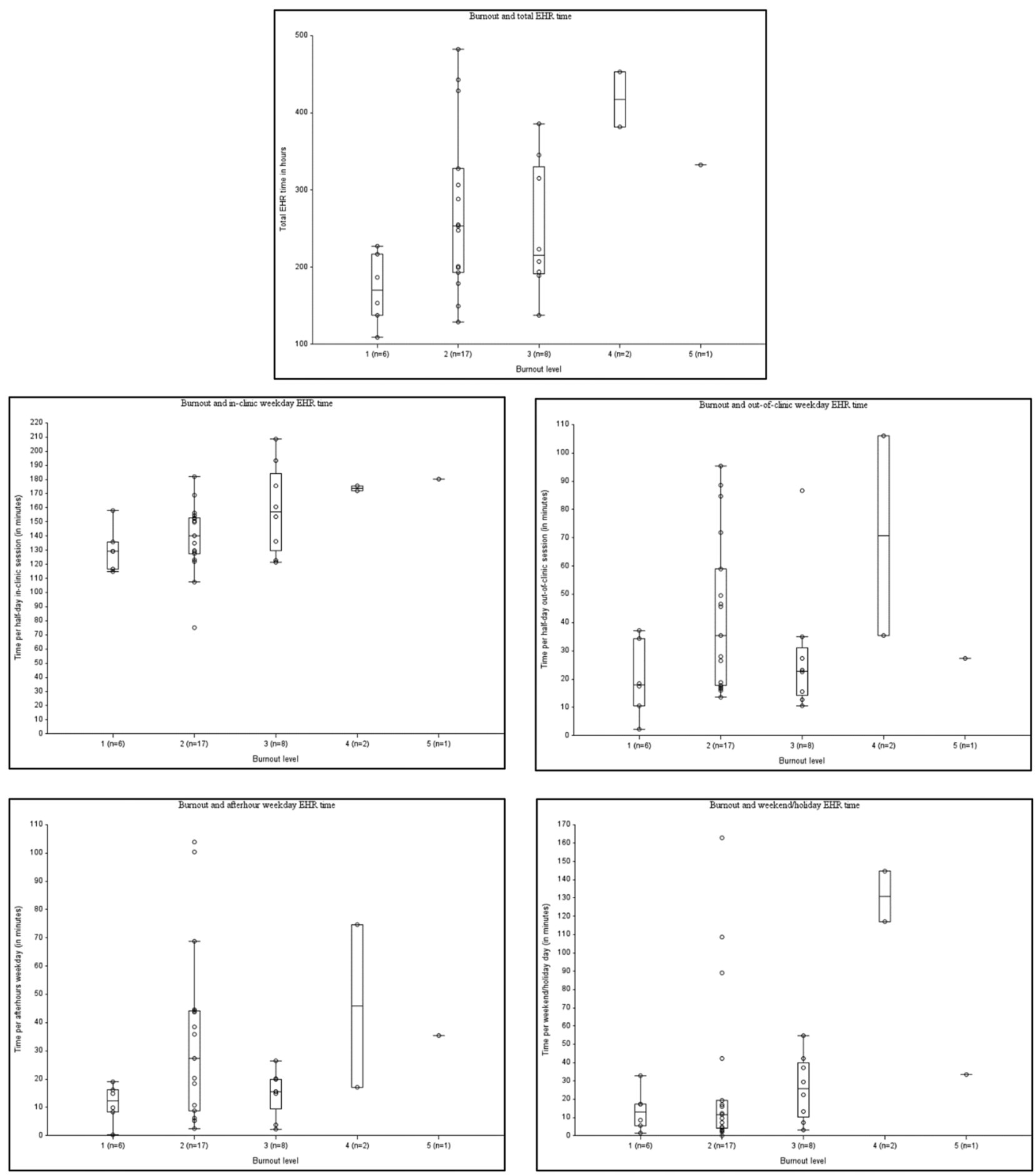

Fig. 1 Bivariate relationship between burnout and electronic health record (EHR) time, by EHR time category $(n=34)$. Each graph represents a scatterplot of burnout ( $x$-axis) and EHR time ( $y$-axis), with a separate graph for each EHR time category. Overlying the scatterplots are boxplots, with bands representing the median, and the top and bottom of the box plot representing the first and third quartiles (respectively).

Observed patterns of EHR use are likely dependent on multiple site-specific characteristics, such as defined work-hours, patients-per-hour requirements, and amount of EHR training and optimization support-which could change over time within organizations. Additional studies including multiple practice sites and larger sample sizes would be needed to help confirm our findings and discern if variation exists between burnout and EHR use in other populations.

\section{Conclusion}

In summary, our results show that burnout among physicians is associated with higher levels of in-clinic EHR use, but not with after-hours EHR use. It is important for future studies to further clarify the relationship between burnout and afterhours EHR use in larger populations and other settings. It is also imperative to better understand the factors involved with 
high-intensity and intrusive EHR use, particularly during clinic sessions when physicians are required to do multiple computer-related tasks while seeing patients. Improved understanding of the dynamics of in-clinic EHR use, including which specific EHR tasks are particularly related to burnout, may lead to focused interventions at the organizational and individual level, such as improved EHR training, ${ }^{25,26}$ the adoption of scribes, ${ }^{23,24}$ or the reduction of waste in data entry and documentation processes. ${ }^{31-33}$ These strategies may ultimately help promote better quality of care and a happier and more stable physician workforce.

\section{Clinical Relevance Statement}

This article presents our findings of an observational cohort study using novel ways to objectively characterize primary care physicians' EHR use, to determine the relationship between burnout and their use of the EHR. We found that burnout is primarily related to EHR use during clinic sessions, and not related to after-hours EHR use. We believe our results may help refine efforts to improve physician burnout, by focusing attention on strategies that specifically help integrate EHR demands with in-clinic care.

Protection of Human and Animal Subjects

This study was performed in compliance with the Belmont Report and the Common Rule (45 CFR 46), and was approved by the UW-Madison Health Sciences Institutional Review Board.

\section{Funding}

This study was supported by Pilot Project funding from the Division of General Internal Medicine at the University of Wisconsin-Madison (grant 233-AAC5738). Additional support was received from the Clinical and Translational Science Award (CTSA) program, previously through the National Center for Research Resources (NCRR) grant 1UL1RR025011, and now by the National Center for Advancing Translational Sciences (NCATS), grant 9U54TR000021. The content is solely the responsibility of the authors and does not necessarily represent the official views of the National Institutes of Health, the Department of Veterans Affairs, or the United States government. This project was also supported by the UW Carbone Cancer Center (UWCC) Support Grant from the National Cancer Institute, grant number P30 CA014520. Additional support was provided by the UW School of Medicine and Public Health from the Wisconsin Partnership Program. We would also like to thank Linda Baier Manwell, MS, for her insightful advice and logistical support throughout this study.

\section{Conflict of Interest}

None declared.

\section{References}

1 Shanafelt TD, West CP, Sinsky C, et al. Changes in burnout and satisfaction with work-life integration in physicians and the general US working population between 2011 and 2017. Mayo Clin Proc 2019;94(09):1681-1694

2 West CP, Dyrbye LN, Shanafelt TD. Physician burnout: contributors, consequences and solutions. J Intern Med 2018;283(06): 516-529

3 Rabatin J, Williams E, Baier Manwell L, Schwartz MD, Brown RL, Linzer M. Predictors and outcomes of burnout in primary care physicians. J Prim Care Community Health 2016;7(01):41-43

4 Shanafelt TD, Mungo M, Schmitgen J, et al. Longitudinal study evaluating the association between physician burnout and changes in professional work effort. Mayo Clin Proc 2016;91(04):422-431

5 Panagioti M, Geraghty K, Johnson J, et al. Association between physician burnout and patient safety, professionalism, and patient satisfaction: a systematic review and meta-analysis. JAMA Intern Med 2018;178(10):1317-1330

6 Hamidi MS, Bohman B, Sandborg C, et al. Estimating institutional physician turnover attributable to self-reported burnout and associated financial burden: a case study. BMC Health Serv Res 2018;18(01):851

7 Friedberg MW, Chen PG, Van Busum KR, et al. Factors affecting physician professional satisfaction and their implications for patient care, health systems, and health policy. Rand Health Q 2014;3(04):1

8 Babbott S, Manwell LB, Brown R, et al. Electronic medical records and physician stress in primary care: results from the MEMO study. J Am Med Inform Assoc 2014;21(e1):e100-e106

9 Coleman M, Dexter D, Nankivil N. Factors affecting physician satisfaction and Wisconsin Medical Society strategies to drive change. WMJ 2015;114(04):135-142

10 Sinsky CA, Dyrbye LN, West CP, Satele D, Tutty M, Shanafelt TD. Professional satisfaction and the career plans of US physicians. Mayo Clin Proc 2017;92(11):1625-1635

11 Sinsky C, Colligan L, Li L, et al. Allocation of physician time in ambulatory practice: a time and motion study in 4 specialties. Ann Intern Med 2016;165(11):753-760

12 Arndt BG, Beasley JW, Watkinson MD, et al. Tethered to the EHR: primary care physician workload assessment using EHR event log data and time-motion observations. Ann Fam Med 2017;15(05): 419-426

13 Kamnetz S, Trowbridge E, Lochner J, Koslov S, Pandhi N. A simple framework for weighting panels across primary care disciplines: findings from a large US multidisciplinary group practice. Qual Manag Health Care 2018;27(04):185-190

14 Williams ES, Konrad TR, Linzer M, et al; SGIM Career Satisfaction Study Group. Society of General Internal Medicine. Refining the measurement of physician job satisfaction: results from the Physician Worklife Survey. Med Care 1999;37(11):1140-1154

15 Linzer M, Manwell LB, Williams ES, et al; MEMO (Minimizing Error, Maximizing Outcome) Investigators. Working conditions in primary care: physician reactions and care quality. Ann Intern Med 2009;151(01):28-36

16 Rohland BM, Kruse GR, Rohrer JE. Validation of a single-item measure of burnout against the Maslach Burnout Inventory among physicians. Stress Health 2004;20(02):75-79

17 Hansen V, Girgis A. Can a single question effectively screen for burnout in Australian cancer care workers? BMC Health Serv Res 2010;10:341

18 Dolan ED, Mohr D, Lempa M, et al. Using a single item to measure burnout in primary care staff: a psychometric evaluation. J Gen Intern Med 2015;30(05):582-587

19 Windover AK, Martinez K, Mercer MB, Neuendorf K, Boissy A, Rothberg MB. Correlates and outcomes of physician burnout within a large academic medical center. JAMA Intern Med 2018;178(06):856-858

20 Mini Z burnout survey. American Medical Association. Available at: https://www.stepsforward.org/modules/physician-burnoutsurvey. Accessed July 26, 2018

21 Altman DG, Royston P. The cost of dichotomising continuous variables. BMJ 2006;332(7549):1080 
22 Shanafelt TD, Dyrbye LN, Sinsky C, et al. Relationship between clerical burden and characteristics of the electronic environment with physician burnout and professional satisfaction. Mayo Clin Proc 2016;91(07):836-848

23 Gidwani R, Nguyen C, Kofoed A, et al. Impact of scribes on physician satisfaction, patient satisfaction, and charting efficiency: a randomized controlled trial. Ann Fam Med 2017;15(05): 427-433

24 Shultz CG, Holmstrom HL. The use of medical scribes in health care settings: a systematic review and future directions. J Am Board Fam Med 2015;28(03):371-381

25 Dastagir MT, Chin HL, McNamara M, Poteraj K, Battaglini S, Alstot L. Advanced proficiency EHR training: effect on physicians' EHR efficiency, EHR satisfaction and job satisfaction. AMIA Annu Symp Proc 2012;2012:136-143

26 Longhurst CA, Davis T, Maneker A, et al; Arch Collaborative. Local investment in training drives electronic health record user satisfaction. Appl Clin Inform 2019;10(02):331-335

27 Belden JL, Koopman RJ, Patil SJ, Lowrance NJ, Petroski GF, Smith JB. Dynamic electronic health record note prototype: seeing more by showing less. J Am Board Fam Med 2017;30(06): 691-700

28 Robertson SL, Robinson MD, Reid A. Electronic health record effects on work-life balance and burnout within the $\mathrm{I}^{3}$ population collaborative. J Grad Med Educ 2017;9(04):479-484

29 Dyrbye LN, West CP, Satele D, Sloan JA, Shanafelt TD. Work/Home conflict and burnout among academic internal medicine physicians. Arch Intern Med 2011;171(13):1207-1209

30 DiAngi YT, Stevens LA, Halpern-Felsher B, Pageler NM, Lee TC. Electronic health record (EHR) training program identifies a new tool to quantify the EHR time burden and improves providers' perceived control over their workload in the EHR. JAMIA Open 2019;2(02):222-230

31 Bain PA. How physicians can save 56 hours per year. WMJ 2017; 116(02):52

32 Ashton M. Getting rid of stupid stuff. N Engl J Med 2018;379(19): 1789-1791

33 Guo U, Chen L, Mehta PH. Electronic health record innovations: helping physicians - one less click at a time. Health Inf Manag 2017;46(03):140-144 